\title{
A transformação do espaço para o Turismo na Rota Turística Gastronômica de Santa Maria e Silveira Martins, RS, Brasil
}

\section{The transformation of space for tourism in the tourist route gastronomic of Santa Maria and Silveira Martins, RS, Brazil}

\author{
Thaís Gomes Torres (TORRES, T. G.) * \\ Elsbeth Léia Spode Becker (BECKER, E. L. S.) ${ }^{\text {** }}$
}

\begin{abstract}
RESUMO - O Turismo é um fenômeno capaz de transformar e reorganizar o espaço geográfico. Entretanto, o Turismo necessita da articulação entre as políticas públicas, o setor privado e a comunidade local e depende da interrelação com diversas ciências. Neste trabalho objetivou-se analisar a transformação socioespacial da Rota Turística Gastronômica nos municípios de Silveira Martins e Santa Maria, Rio Grande do Sul, Brasil. A metodologia utilizada foi a pesquisa teórica, a consulta a uma ampla bibliografia que norteia os temas propostos e a coleta de dados. Esses dados foram obtidos por meio de pesquisas de campo na Rota Turística Gastronômica de Santa Maria e Silveira Martins, de visitas pré-estabelecidas, de leitura em jornais locais, e de material fotográfico. Na discussão dos resultados, foi possível verificar que a Rota Turística Gastronômica se enquadra na modalidade de turismo rural e possui territorialidades que se misturam no espaço para representar a rota como um forte produto turístico da região Central do Rio Grande do Sul.
\end{abstract}

Palavras-chave: Território; Rota Turística Gastronômica de Santa Maria e Silveira Martins; Poder público

\begin{abstract}
Tourism is a phenomenon that is capable to change and reorganize the geographic space. Therefore, in order to trigger this relation net, Tourism needs articulation among public policies, private segment and local community and also depends on interrelation with several sciences. In the present work the main purpose is to evidence Geographic Science concepts that contribute for an analysis of the social and spacial transformation of the Gastronomic Touristic Route in the municipalities of Silveira Martins and Santa Maria, Rio Grande do Sul, Brasil. The following work aimed mainly to conduct an analysis on the transformation of the space of the municipalities Santa Maria and Silveira Martins for the Tourism at the Gastronomic Touristic Route of Santa Maria and Silveira Martins. The methodology used was the theoretical research, the study of a wide bibliography guiding the proposed topics and the collection of data. These data were obtained through field researches in the Gastronomic Touristic Route, with pre set visits, reading of local newspapers, and photography storage. In the discussion of the results, it was possible to notice that the Gastronomic Touristic Route presents distinct territorialities that set though many uses: local community, private sector, and public sector.
\end{abstract}

Key words: Territory; Touristic Route of Santa Maria and Silveira Martins; Public Power

\footnotetext{
* Bacharel em Turismo pelo Centro Universitário Franciscano (UNIFRA). Mestranda em Geografia da Universidade Federal de Santa Maria (UFSM). Endereço: Avenida Roraima, 1000, Cidade Universitária Bairro Camobi. CEP 97105-900 - Santa Maria - RS (Brasil). Telefone: (55) 3220-8908. Email: thaisturis@gmail.com

** Licenciatura e Bacharelado em Geografia pela Universidade Federal de Santa Maria (UFSM). Mestrado em Engenharia Agrícola (UFSM). Doutorado em Agronomia (UFSM). Professora Doutora do Curso de Geografia (UNIFRA). Endereço: Rua dos Andradas, 1614 - Centro. CEP: 97010-032 - Santa Maria, RS (Brasil). Telefone: (55) 3222-0001. Fax: (55) 3222-6484. E-mail: elsbethleia @ terra.com.br
} 


\section{INTRODUÇÃO}

O Turismo, ao ser analisado como fenômeno espacial e social, acompanha os deslocamentos humanos motivados por diferentes razões como: procura de alimentos, necessidade de transportar informações, imagens, carga ou pessoas. Esses deslocamentos se intensificaram por meio da abertura de estradas e do desenvolvimento dos meios de transportes. Está associado à expansão das forças produtivas e do desenvolvimento do capitalismo, vetor de mudanças, que vêm produzindo novas configurações sócio-espaciais, tanto no meio urbano, como no meio rural, em diferentes escalas.

As inovações tecnológicas, os meios de transportes e comunicações foram fundamentais na reorganização das sociedades e dos espaços geográficos. De acordo com a lógica capitalista, a produção e a reprodução dos espaços, a modernização e a tecnificação alteraram as relações sociais e econômicas que necessitaram buscar novos mercados para contornar as crises, criar novas ofertas e diversificar produtos. Pode-se dizer que o Turismo foi beneficiado pelo processo de globalização. Segundo Giddens (1991, p. 69),

\footnotetext{
A globalização pode ser definida como a intensificação das relações sociais em escala mundial, que ligam localidades distantes de tal maneira que acontecimentos locais são modelados por eventos ocorridos a muitas milhas de distância.
}

De maneira geral, o mundo atual é movido pela comunicação, rapidez dos transportes, tecnologias avançadas, internet e aumento de demanda por Turismo.

Percebe-se que o crescimento do Turismo tem despertado interesse dos órgãos públicos, privados e da comunidade local em investir e apoiar o segmento como alternativa de renda para os produtores rurais e para dinamizar a renda dos municípios que fazem parte da Rota Turística Gastronômica de Santa Maria e Silveira Martins, Rio Grande do Sul, objeto do presente estudo.

O Turismo é capaz de fornecer novas alternativas para aqueles que não se adaptaram com a idéia de retirar-se do campo, abrindo espaço para agricultores e, principalmente, para a mulher rural reconfigurar suas relações dentro de um novo território, o território turístico. No processo histórico, surgem oportunidades como 
Agroturismo, Ecoturismo, Turismo Rural, em que o objetivo é sempre valorizar as relações do homem com a natureza.

O Turismo se consolida como uma importante atividade econômica e social no século XX, por possuir capacidade de deslocar milhares de pessoas as quais utilizam seu tempo livre para viajar. Segundo a Organização Mundial de Turismo (OMT, 2003), o Turismo é a soma de relações e de serviços resultantes de mudanças temporárias e voluntárias de residência, motivadas por razões alheias a negócios ou profissionais.

No entanto, é necessário reforçar o entendimento que o Turismo não implica atrelar-se apenas à economia. Para Candiotto (2007),

\footnotetext{
O Turismo também carrega consigo diversas transformações socioespaciais de ordem sociocultural, política e ambiental. O Turismo não é, portanto, responsável somente pelo intercâmbio econômico e geração de divisas, mas principalmente pela produção e pelo consumo do espaço geográfico, envolvendo aspectos como a transformação de paisagens, de ecossistemas e de manifestações culturais em mercadoria; e também é responsável pelo estabelecimento de novas relações sociais, levando a mudanças nos territórios e nas territorialidades (CANDIOTTO, 2007, p. 2).
}

Devido à grande expressividade, o Turismo tem despertado o interesse de diversas ciências que se propõem analisar e decodificar esse fenômeno. Recentemente, geógrafos e outros pesquisadores têm reconhecido a relevância da abordagem do Turismo dentro de uma perspectiva científica (SILVEIRA, 2002). A Geografia possui em seus aportes metodológicos ferramentas que possibilitam uma abordagem adequada de como o Turismo concebe e modifica os espaços e quais as transformações que disso decorre na paisagem. A abordagem que a Geografia vem dedicando ao Turismo referese especialmente à

[...] mobilização dos fluxos dos visitantes, de capital, de trabalhadores prestadores de serviços, dos padrões de ocupação, das modificações do uso do espaço, das transformações do valor do solo urbano, produzindo nova ordem espacial (CORIOLANO, 2000, p. 20).

A organização espacial, enquanto objeto de análise da Geografia e do Turismo é a principal justificativa para o tema proposto neste artigo, estando associada ao fato da importância que a atividade turística vem alcançando no ordenamento do espaço, sendo capaz de provocar mudanças ao longo dos tempos na forma e função dos municípios, podendo fornecer novas funcionalidades para este espaço. 
A base de estudo foi a Rota Turística Gastronômica de Santa Maria e Silveira Martins, Rio Grande do Sul, Brasil que foi formatada como produto turístico ${ }^{1}$ no ano de 2005. O objetivo da Rota Turística Gastronômica de Santa Maria e Silveira Martins é valorizar o caminho percorrido pelos imigrantes italianos, os quais chegaram a Silveira Martins e Santa Maria em 1887, ofertar uma alternativa de renda para os produtores rurais, dinamizar a economia de Santa Maria e Silveira Martins, resgatar e preservar a cultura por meio da gastronomia, valorizar as potencialidades naturais, culturais, históricas para o desenvolvimento local e regional baseando-se em princípios de sustentabilidade.

Swarbrooke (2000) afirma que o Turismo sustentável pode criar um clima favorável na opinião de consumidores e uma política de governo em que as organizações possam competir na base de quem age de forma mais sustentável.

O presente trabalho buscou entender as relações do setor público com o privado e a comunidade local na Rota Turística Gastronômica de Santa Maria e Silveira Martins a partir de diferentes territorialidades encontradas no espaço da rota.

\section{CATEGORIAS DE ANÁliSE DO ESPAÇO: APONTAMENTOS HISTÓRICOS E FÍSICOS DE SANTA MARIA E SILVEIRA MARTINS, RS}

Para analisar e explicar o espaço da sociedade, visto que toda mudança social provoca novas reorganizações no espaço geográfico, Santos (1997) propõe categorias de análise do espaço que consistem em: Forma, Função, Estrutura e Processo. Estas categorias de análise, segundo conceitos de Rodrigues (1999), permitem entender a dinâmica espacial do Turismo dentro de um contexto tanto horizontal quanto vertical numa perspectiva de interação entre os elementos do espaço.

A forma corresponde à parte visível pelo observador e ao arranjo dos objetos físicos no espaço. No caso da Rota Turística Gastronômica de Santa Maria e Silveira Martins, a forma se expressa na paisagem presente e suas transformações ocorridas no final do século XIX e início do XX até o presente nos municípios de Santa Maria e Silveira Martins. A forma representada pela paisagem no Turismo apresenta uma

\footnotetext{
${ }^{1}$ Soma dos atrativos, equipamentos e serviços turísticos.
} 
dinamicidade que é expressa pela história da imigração italiana e pelas mudanças das relações sociais com o meio natural.

Karsburg (2007) relata que em 1880, Santa Maria e Silveira Martins apresentavam forma tipicamente de cidades rurais; vilas coloniais. As relações sociais eram marcadas por encontros aos domingos nas igrejas, famílias dedicavam-se exclusivamente ao trabalho nas lavouras, seu comércio era restrito devido à precariedade de deslocamento, as técnicas utilizadas na produção de alimentos eram rudimentares e, muitas vezes, sem condições de higiene. A religiosidade é fator importante na história de Santa Maria e Silveira Martins.

Desde a imigração italiana, o sistema de colonização do governo brasileiro distribuía os imigrantes em lotes rurais, a vida social dos imigrantes dava-se em função da igreja. Domingo era considerado dia sagrado, era proibido trabalhar na lavoura, precisavam dedicar o dia a rezar. Ao se fixarem no lotes, logo providenciavam um lugar em comum para orar. Inicialmente, as igrejas eram construídas de madeiras, logo após sendo construídas igrejas em pedras ou tijolos. As relações entre as autoridades municipais de Santa Maria e os italianos de Silveira Martins ficavam submetidas ao Ministério da Agricultura, sob jurisdição do governo central no Rio de Janeiro (ISAIA, 1987).

No que diz respeito à localização, o município de Santa Maria posiciona-se na Depressão Central do Rio Grande do Sul. Limita-se ao Norte com os municípios de São Martinho da Serra, Júlio de Castilhos e Silveira Martins; a Leste com o município de Restinga Seca; ao Sul com os municípios de Formigueiro, São Sepé e parte de município de São Gabriel; a Oeste, com o município de São Gabriel e os municípios de Dilermando de Aguiar e São Pedro do Sul.

De acordo com Viero (2003), o relevo do município apresenta três feições distintas: Planícies Aluviais, Coxilhas e Região Serrana. No município encontra-se um dos mais importantes sítios geológicos do Brasil, Sítio da Alemoa, localizado a 4 km do centro no entroncamento da BR 158 onde foram encontrados fósseis de répteis. De acordo com dados do IBGE (2009) o município foi criado em 16 de dezembro de 1857 e instalado em 17 de maio de 1858. Atualmente, possui população de 270.073 mil habitantes fixos, sendo a $5^{\text {a }}$ maior cidade do Estado em população, depois de Porto Alegre, Caxias do Sul, Pelotas e Canoas (IBGE, 2009). 
A hidrografia é constituída, principalmente pelos rios Vacacaí, Vacacaí - Mirim e os rios Ibicuí - Mirim e Guassupi na bacia do Uruguai. O tipo climático do município é o subtropical, com temperatura média anual em torno de $19^{\circ} \mathrm{C}$. As médias de temperaturas mais baixas são verificadas nos meses de julho e agosto. No inverno, são comuns as geadas (VIERO, 2003).

As bases econômicas atuais do município resultam dos processos qualitativos que alteram a forma e a função da cidade. Desde a instalação da ferrovia de Santa Maria a cidade passou a ter relevância no setor terciário, destacando-se o comércio. $\mathrm{O}$ espaço foi processualmente construído e no presente novas bases econômicas compõem a forma e alteram a função de Santa Maria com os serviços públicos, incluindo a Universidade Federal de Santa Maria (UFSM), e os militares.

O processo migratório desencadeado no sul do país, durante o período do Brasil Império teve grande importância na ocupação da região da Quarta Colônia de imigração italiana $^{2}$.

Segundo Karsburg (2007) no ano de 1875, com a unificação da Itália e a necessidade de ocupação da região serrana da Província de São Pedro do Rio Grande do Sul, chegaram as primeiras levas de imigrantes italianos nas Colônias de Campo dos Bugres, Dona Isabel e Conde D'Eu?, convertendo-se posteriormente em Caxias do Sul, Garibaldi e Bento Gonçalves respectivamente. Estavam formadas as três colônias de imigração italiana do RS. Porém, com o sonho de fazer a América, muitos italianos continuaram vindo para o Brasil (ISAIA, 1987). Dom Pedro II, por meio de seu aliado senador do império, Gaspar da Silveira Martins, percebeu a necessidade de povoar a Serra de São Martinho, fazendo defesa ao norte e nordeste para a intendência de Santa Maria da Boca do Monte (IBGE, 2009). Surge, então, mais uma colônia de imigração italiana no RS, chamada inicialmente de Città Nuova, depois Città Bianca e mais tarde de Silveira Martins, em homenagem ao seu intercessor no império, Gaspar da Silveira Martins.

Devido às guerras, às péssimas condições de trabalho e de alimentos, ao aumento da população e da pobreza, a Itália não estava sendo um país que oferecia condições de sobrevivência nem expectativas de vida aos cidadãos italianos. Dessa maneira, os agricultores italianos precisaram pensar em uma solução para melhorarem

\footnotetext{
${ }^{2}$ Nome dado ao quarto centro de imigração italiana no estado do Rio Grande do Sul. As primeiras colônias foram o que hoje representa as cidades de Caxias do Sul, Bento Gonçalves e Garibaldi.
} 
de vida. Foi pensando nessa situação em que se encontrava a Itália que o governo brasileiro logo após a abolição da escravatura, necessitava de operários para trabalhar na agricultura e auxiliar na colonização do território. Diante da situação econômica e histórica da Itália, foi estimulada a vinda dos italianos para povoar suas terras, pois precisavam de mão-de-obra na agricultura.

Os imigrantes vindos para o Brasil abandonaram seu território na busca de melhores oportunidades de vida. Esse tipo de territorialidade se caracterizou como processo territorial material que fez com que os italianos viessem para o Brasil buscar abrigo, recursos e obtenção de lucro e não pelo aspecto simbólico do Brasil, pois os italianos sentiam muita ligação e forte identidade com sua terra.

Em 1884, os 1.650 lotes devolutos já haviam sido ocupados, fato que levou aos imigrantes adquirirem, dos fazendeiros portugueses, mais 3.000 lotes, criando o complexo colonial Silveira Martins. Em 1884, o império deu início ao processo de emancipação política da ex-colônia (KARSBURG, 2007).

Segundo Isaia (1987) foi em 1886, que a colônia de Silveira Martins foi dividida entre os municípios de Santa Maria, Vila Rica (Júlio de Castilhos) e Cachoeira do Sul. Silveira Martins passou a fazer parte como o $4^{\circ}$ Distrito de Santa Maria. Posteriormente, em 1988, Silveira Martins conseguiu a sua emancipação política de Santa Maria.

A origem do nome Silveira Martins deu-se em homenagem ao grande tribuno rio-grandense Gaspar de Silveira Martins, que era senador do império na época do processo de colonização e imigração no Rio Grande do Sul.

Dados do IBGE (2009) indicam que Silveira Martins possui uma área geográfica de $120 \mathrm{~km}^{2}$, uma população de 2.479 habitantes e tem a economia centrada na produção primária e no Turismo, em especial o gastronômico. Entre os produtos primários destacam-se: milho, feijão, soja, gado (PORTAL DA QUARTA COLÔNIA, 2009).

O município de Silveira Martins pertence à Macroregião Sul do país, Mesoregião Centro - Ocidental Rio-Grandense e a Microregião de Restinga Seca no estado do Rio Grande do Sul, conforme a classificação do Instituto Brasileiro de Geografia e Estatística (IBGE, 2009). 
Situada sobre a Serra de São Martinho, na Serra Geral, localmente denominado de Rebordo do Planalto, é uma das áreas piloto da Reserva de Biosfera da Mata Atlântica no Estado e apresenta clima subtropical úmido.

A compreensão dos aspectos físicos e históricos dos municípios de Santa Maria e Silveira Martins são considerados como um conjunto indissociável dos objetos no espaço geográfico e das relações sociais.

Alguns marcos qualitativos, segundo Karsburg (2007), foram significativos para a transformação do espaço de Santa Maria e Silveira Martins como: instalação da ferrovia em 1885 (figura 1) que resultou na modificação comportamental dos homens e seus hábitos alimentares, seus costumes de trabalho e, principalmente, suas relações sociais, conflito Igreja versus Governantes onde a igreja era contra as idéias de progresso e desenvolvimento que os governantes almejavam para Santa Maria, chegada dos imigrantes italianos em Silveira Martins, em 1887, na busca por melhores condições de vida e esperança de prosperar e fazer riqueza.

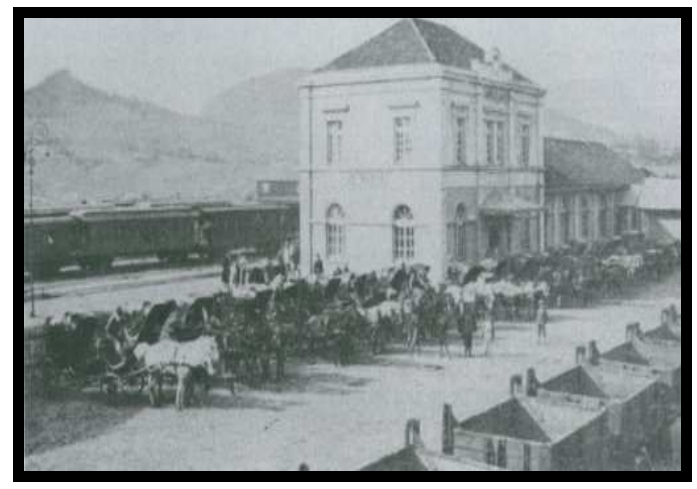

FIGURA 1: INAUGURAÇÃO DA FERROVIA EM 1885. FONTE: KARSBURG, 2007.

A nova função dos municípios alterou-se no tempo, com novas atividades econômicas inseridas no espaço, introdução dos meios de comunicação e de transportes. Tais fatos foram fundamentais para transformar a antiga vila rural em uma forma nova de estilo das edificações que pode ser visualizada na arquitetura dos prédios e das casas as quais foram modificadas com a expansão urbana de Santa Maria. Assim, a modificação da forma e da função se alterou de acordo com as mudanças na sociedade.

Quanto a estrutura, natural e artificial, diz respeito à inter-relação entre as demais categorias: forma, função e processo. Por meio da estrutura observa-se que os 
municípios de Santa Maria e Silveira Martins no tempo presente são diferentes daqueles que tinham única função de dedicação a igreja e trabalho na agricultura. A estrutura natural do município de Silveira Martins desperta interesse de apropriação e valorização do espaço por parte do setor imobiliário em territorializar espaços. A instalação do campus da Universidade Federal de Santa Maria em Silveira Martins no ano de 2009 criou nova territorialidade no espaço. Tal fato engendra na ocupação do espaço natural, e produção de uma estrutura artificial para atender uma nova demanda de mercado. A nova estrutura acarreta modificações na atual organização do espaço de Silveira Martins.

Os municípios de Santa Maria e Silveira Martins sofreram efeitos do processo. No passado, aproximadamente em 1889 (figura 2) os governantes pensaram novas funcionalidades para os espaços, e assim criaram opções para o lazer. O Turismo surgiu em meio às idéias de progresso. Nessa época, ocorreram mudanças na arquitetura das casas, construção de prédios, o teatro Treze de Maio foi construído no lugar da antiga Igreja Matriz, fato que representou a modernidade e a ruptura do poder da igreja. (KARSBURG, 2007)

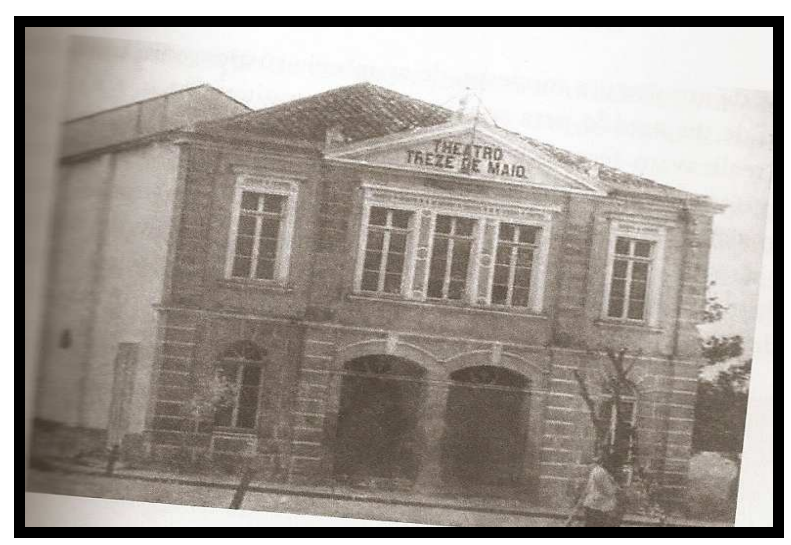

FIGURA 2: TEATRO TREZE DE MAIO EM 1889.

FONTE: KARSBURG, 2007.

A modernidade alterou a forma e a função dos municípios e, ao longo dos anos, as mudanças sociais se refletiram nos hábitos e costumes das pessoas que começaram a viajar para outras cidades e pensar em lazer. Santos (1997) afirma que novas organizações espaciais, refletem a sociedade no espaço.

As relações entre os diversos elementos do espaço é muito importante, pois pressupõe interdependência funcional entre eles. Assim, "forma, função, processo e 
estrutura devem ser estudados concomitantemente e vistos na maneira como interagem para criar e moldar o espaço através do tempo" (SANTOS, 1997, p. 52). Essa relação é ilustrada na figura 3 por (RODRIGUES, 1999). Rodrigues (1999) refletiu sobre essas categorias associando-as ao Turismo esquematizando na figura abaixo.

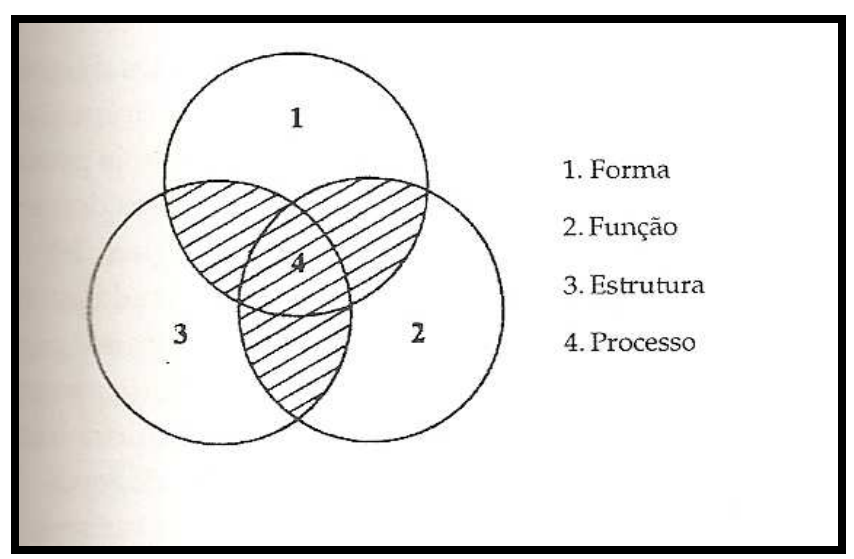

FIGURA 3: CATEGORIAS DE ANÁLISE DO ESPAÇO.

FONTE: ADAPTADO DE RODRIGUES (1999, P. 71)

Tal análise espacial permite entender a produção de novos espaços pelo Turismo, particularmente a criação da Rota Turística Gastronômica em Santa Maria e Silveira Martins, RS. A Rota está localizada nos municípios de Santa Maria e Silveira Martins (figura 4). Os objetos naturais vão transformando-se em objetos sociais no processo de valorização e inserção no espaço pelo Turismo. Rodrigues (1999) analisa que quando se estuda a organização espacial, estas categorias são necessárias para explicar como o espaço social está estruturado, como os homens se organizam e como a concepção e o uso que se faz do espaço sofrem mudanças. A acumulação do tempo histórico dos municípios de Santa Maria e Silveira Martins permite compreender a atual organização espacial com a inserção da Rota Turística Gastronômica. 


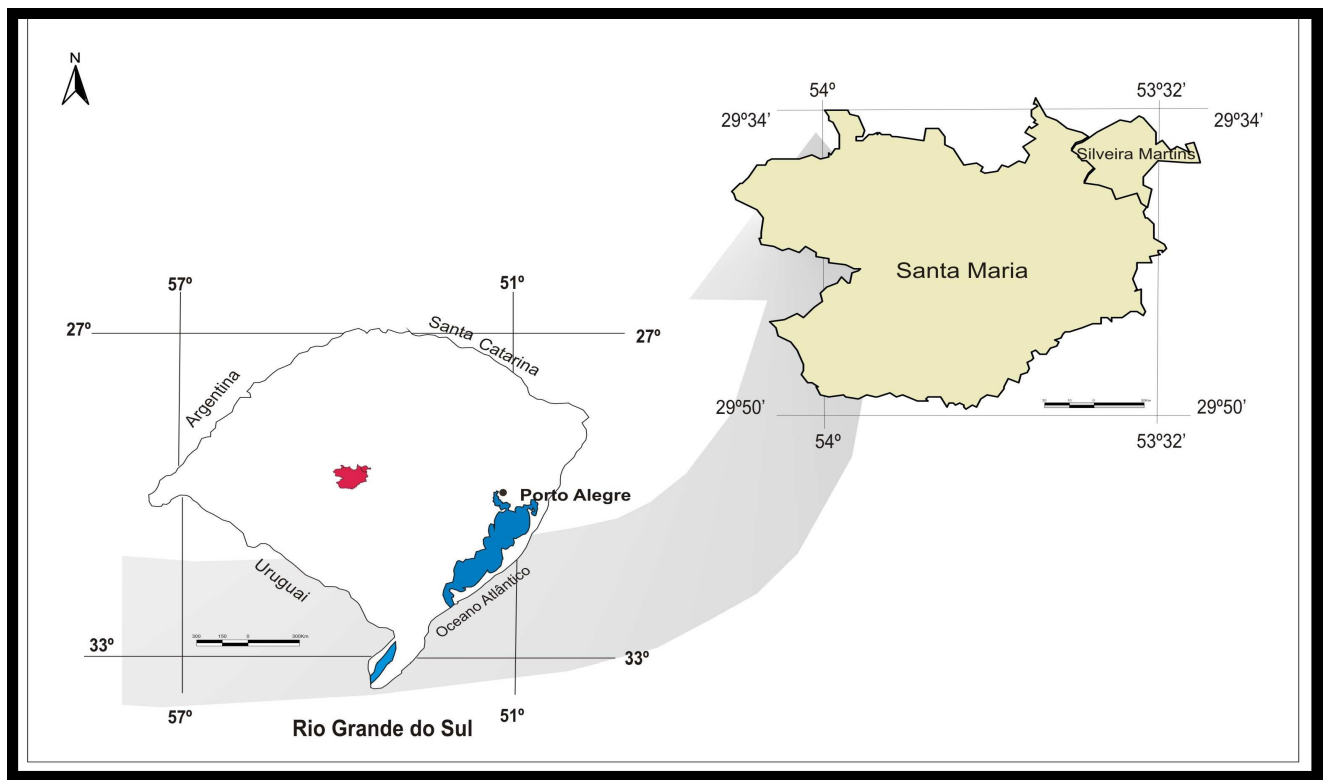

FIGURA 4: LOCALIZAÇÃO DE SANTA MARIA E SILVEIRA MARTINS, RIO GRANDE DO SUL. ELABORAÇÃO CARTOGRÁFICA: VANESSA DE OLIVEIRA, 2009.

\section{ROTA TURÍSTICA GASTRONÔMICA SANTA MARIA - SILVEIRA MARTINS}

A Rota Turística Gastronômica Santa Maria e Silveira Martins foi criada pelo poder público de Santa Maria e Silveira Martins para resgatar e valorizar o caminho percorrido pelos imigrantes italianos, preservar a cultura e história do lugar e, principalmente, agregar valor na renda dos proprietários rurais e gerar empregos e oportunidades. Ademais, devido à proximidade entre os municípios de Santa Maria e Silveira Martins e do constante fluxo de pessoas que visitam os empreendimentos gastronômicos (cantinas, restaurantes), as agroindústrias, fábricas de facas em Arroio Grande (distrito de Santa Maria) e Silveira Martins, existe um grande potencial em desenvolver o Turismo nos dois municípios.

A Rota Turística Gastronômica encaixa-se na modalidade de Turismo classificada como Turismo Rural e apresenta uma nova alternativa de renda para produtores rurais comercializarem seus produtos e valorizarem a cultura local. As rotas gastronômicas, ou rotas alimentares representam a combinação da gastronomia local/regional combinada com os atrativos ambientais, históricos e culturais de uma região (LINDNER, 2007). 
Unidos com o objetivo de impulsionar o Turismo na região central do Rio Grande do Sul, Santa Maria e Silveira Martins assinaram um protocolo de intenções em 22 de março de 2005 e formataram o produto Rota Turística Gastronômica após evidenciar uma oferta diversificada de atrativos tanto naturais quanto culturais que inicialmente se encontravam desarticulados e também de uma demanda de turistas vindos da cidade de Santa Maria que se deslocavam até Silveira Martins.

Os protagonistas responsáveis pela criação da Rota Turística Gastronômica organizaram o produto turístico a partir de uma oferta já existente, pois quase todos os empreendimentos já existiam, ou já ofereciam e comercializavam produtos antes mesmo da criação da rota. Esse fato demonstra que a maior parte dos empreendimentos que compõem a oferta turística da rota já fazia parte do cotidiano dos empreendedores e de algumas pessoas da comunidade local, apresentando-se como horizontalidades no espaço.

O projeto de criação da rota obteve financiamento do Ministério do Desenvolvimento Agrário (MDA) - Governo Federal, Programa PRONAT ${ }^{3}$ - Contrato 178.851-40 e Caixa Econômica Federal. A verba foi de 72 mil reais destinadas R\$ 40.000,00 - Sinalização e R\$ 32.000,00 - Infra-estrutura (RUVIARO, 2007).

A criação da Rota aconteceu devido a um forte interesse dos proprietários, das prefeituras municipais de Santa Maria e Silveira Martins e também da comunidade local. Os técnicos realizaram visitas aos empreendimentos já existentes, fizeram um levantamento prévio das potencialidades turísticas e chamaram todos interessados, independente de possuir ou não algum empreendimento.

Dessa forma, entendeu-se que a idéia foi local e houve uma consulta popular, pois, partiu de diálogos horizontais entre os setores público, privado e comunidade local. É fundamental uma ampla participação da população local no planejamento e na gestão do Turismo, a comunidade deve desejar que o Turismo se desenvolva. Para isso, a prefeitura realizou visitas para saber a opinião das pessoas.

Uma ação importante das prefeituras de Santa Maria e Silveira Martins para divulgar a Rota Turística Gastronômica de Santa Maria e Silveira Martins consistiu na utilização de um apelo étnico/cultural e da diversidade de atrativos que a rota apresenta para diferenciá-la de outras rotas turísticas do Rio Grande do Sul. Isso se deu em virtude

\footnotetext{
${ }^{3}$ Programa Nacional de Desenvolvimento Territorial
} 
da colonização dos imigrantes italianos em Silveira Martins, que ainda preserva fortes traços da herança italiana na arquitetura das casas, nas festividades, gastronomia, produção de vinhos na paisagem e nas territorialidades de seus habitantes mais antigos.

A Rota Turística e Gastronômica de Santa Maria e Silveira Martins tem 46 pontos de visitação entre o distrito de Arroio Grande em Santa Maria e Silveira Martins. A rota possui balneários, mirantes, cascatas, fábricas de facas, cantinas, restaurantes, moinho, museu, igrejas, capelas, monumentos, propriedades especializadas em Turismo rural e ecoturismo (figura 5).

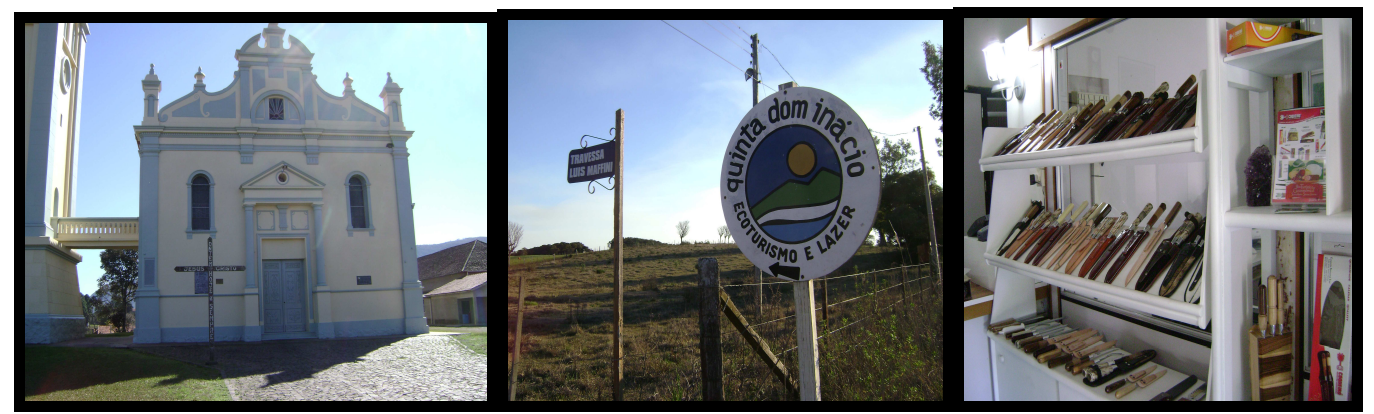

FIGURA 5: ALGUNS ATRATIVOS DA ROTA TURÍSTICA GASTRONÔMICA: PARÓQUIA SÃO PEDRO, QUINTA DOM INÁCIO E FÁBRICA DE FACAS COQUEIRO.

FONTE: THAÍS TORRES, 2009.

O conceito de território apresentou relevante importância no estudo da construção do espaço pela atividade turística e ao desvendar a complexidade de análise da espacialidade do Turismo. Em especial, envolve as rotas turísticas, sendo possível destacar as diferentes territorialidades que os imigrantes italianos tiveram no século XIX ao territorializarem a Serra de São Martinho, atual Silveira Martins considerada berço da Quarta Colônia e Arroio Grande distrito de Santa Maria.

A análise da territorialidade do Turismo, tendo como objeto de estudo uma Rota Turística Gastronômica permite esclarecer o processo de dominação e apropriação do espaço pelo Turismo e como ele pode contribuir na organização e (re)organização do espaço. Atreladas ao Turismo, surgem novas funcionalidades para o espaço. Pode-se prever a melhoria da produção agrícola, um incremento nos produtos rurais, graças à procura por alimentos naturais que se contrastam com alimentos industrializados.

Toda transformação materializada que ultrapassa os recortes temporais estabelece imposições às novas ações condicionando-as. O território de modo análogo é condicionado pelas forças produtivas e sociais que num gradativo processo de 
materialização se transforma em novo. Perante as velhas materializações, produzirá relação peculiar de espaço-tempo que representa a racionalidade vigente atrelada ao poder que conduz esta ação.

A produção territorial está ligada à relação espaço-tempo, envolvendo uma relação dialética entre homem, tempo e espaço. Nesse sentido, assume um movimento absoluto de renovação que difere nas escalas temporais, espaciais, produzindo a singularidade das características de cada território, numa abordagem espiral, que não retorna seu início, mas constrói o novo.

As territorialidades dependem das intenções de quem territorializa e dos sonhos e desejos de prosperar, como aconteceu com os primeiros imigrantes que chegaram no século XIX e fixaram-se em Silveira Martins motivados pelo desejo de prosperar riqueza.

\subsection{A ROTA TURÍSTICA GASTRONÔMICA DE SANTA MARIA E SILVEIRA MARTINS COMO TERRITÓRIO TURÍSTICO}

A institucionalização da Rota Turística criou um novo território, ou seja, o território turístico. O território turístico se formou por meio de uma prática social e uma rede de interesses e exercício de poder que envolveram os fatores sociais, políticos e econômicos dos atores envolvidos como empresários, população local, setor público que almejavam o desenvolvimento local/regional com a inserção do Turismo. Rodrigues (2006) refere-se ao território turístico, como um espaço que assume um sentido multiescalar e multidimensional que só pode ser devidamente apreendido numa concepção maior de multiterritorialidade. O produto turístico Rota Turística Gastronômica de Santa Maria e Silveira Martins não corresponde apenas a um determinado tipo de atrativo, ele é a soma dos aspectos geográficos, históricos, culturais, equipamentos e serviços constituintes no espaço. Possui caráter dinâmico e integrador do espaço geográfico, assim, como o conceito de território apresenta múltiplas dimensões e escalas. Haesbaert (2004, p. 127) afirma que "muito mais do que uma coisa ou um objeto, o território é um ato, uma ação, uma relação, um movimento". È por isso que o território da rota se define na atual sociedade contemporânea por meio de representações simbólicas e culturais (gastronomia) e também pela relação mais concreta (política econômica). 
Ao analisar o território turístico Castro analisa que:

[...] o turismo constrói novos territórios e territorialidades ao promover inovações relacionadas a infra-estrutura energética, de transportes e comunicações, saneamento básico, expansão imobiliária com valorização do solo urbano; ao afetar valores, costumes e cultura da comunidade local, resultando uma série de efeitos favoráveis e desfavoráveis ao inscrever uma nova racionalidade espacial, numa conexão sistêmica entre o local e o global (CASTRO, 2006, p. 42).

Este, assim como todos os outros territórios, é carregado por intencionalidades e relações de poder. Apesar da existência da maior parte da oferta antes da criação da rota, a formatação do produto turístico aproximou os empreendedores que atuavam individualmente, e também articular atrativos que se encontravam dispersos.

O interesse da comunidade local somado aos interesses das prefeituras dos municípios de Santa Maria e Silveira Martins foi fundamental para impulsionar a Rota Turística Gastronômica e criar uma Associação, a "Associação Rota Turística Gastronômica" que é responsável por gerir a rota e avaliar a entrada de cada novo empreendimento através de reuniões mensais com todos associados.

Essas territorialidades se formam por meio de ações que valorizam os objetos distribuídos no espaço e determinam a territorialidade turística. Luchiari (2000, p. 123), afirma que "um novo sistema de objetos é introduzido nos lugares para adequar e dar familiaridade ao novo sistema de ações trazido pela demanda social do turismo". Essa demanda social que a cada dia coloca o Turismo como uma das mais importantes atividades do mundo é responsável por deslocar milhares de pessoas, movimentando bilhões em divisas no mundo inteiro. Por isso deve-se pensar o Turismo como um fator constitutivo das sociedades atuais e não apenas uma atividade exógena do espaço e da sociedade (CASTROGIOVANNI, 2004).

Pode- se afirmar que o território turístico da Rota Turística Gastronômica, é composto por diversos atrativos gastronômicos, culturais, religiosos, naturais, empreendimentos, o poder público com suas ações voltadas para a rota, e outros atores endógenos e exógenos envolvidos na rota turística.

A territorialização turística da Rota Turística Gastronômica se iniciou antes da formatação do produto rota, pois alguns empreendimentos, como exemplo, os restaurantes constituíram a oferta inicial da rota e já existem há muitos anos. Outro fator esta relacionado ao intenso fluxo de visitantes que os restaurantes recebiam nos finais 
de semana. No entanto, a formação do território turístico da rota é consolidada somente com a assinatura de um protocolo de intenções entre os dois municípios. A formação do território Rota Turística Gastronômica se consolida com a entrada de planejadores, consultores, técnicos, empreendedores, agências e pousadas. A rede de relações, portanto, é uma rede complexa que integra múltiplas diversidades. E nessa rede de relações, o Turismo não transforma o espaço sozinho, depende de um conjunto de relações que envolvem outros setores e outras atividades para se desenvolver.

É possível dizer que a Rota Turística Gastronômica impulsionou a territorialização turística nos municípios de Santa Maria e Silveira Martins. A Associação Rota Turística Gastronômica foi criada a partir das necessidades de planejamento, organização e para dar continuidade e sustentabilidade ao produto turístico. Juntamente aos empreendedores, setor público, a Associação atua com ações em torno da estruturação e divulgação da Rota Turística Gastronômica de Santa Maria e Silveira Martins.

Cabe ressaltar que, dentro do território da Rota Turística Gastronômica, existem diversos subterritórios, pois cada empreendimento seja o empreendimento dos restaurantes, agroindústrias, fábricas de facas, pousada, casa de café colonial, agência ou museu apresenta-se como um território específico, com intencionalidades próprias de quem se insere no espaço, neste caso os empreendedores. Nestes territórios existem relações de poder que influenciam nas decisões e nas ações coletivas em torno do produto turístico.

\section{CONSIDERAÇÕES FINAIS}

A partir das abordagens contidas neste artigo, verificou-se que o conceito de território apresenta relevante importância no estudo do espaço pela atividade turística ao desvendar a complexidade de análise da espacialidade do Turismo em especial a que envolve as rotas turísticas sendo possível destacar as diferentes mudanças ocorridas no espaço de Santa Maria e Silveira Martins, que proporcionaram a criação da Rota Turística Gastronômica de Santa Maria e Silveira Martins. 
A Rota Turística e Gastronômica de Santa Maria e Silveira Martins localiza-se num cenário natural de vales e morros com vegetação nativa e florestada, irrigada por pequenos córregos e arroios que emprestam uma paisagem bucólica, de descanso e que, por um lado, são aproveitados para atividades como o Turismo de aventura, principalmente, realização de trilhas. Ainda permite ao turista desfrutar de um cenário histórico-cultural rico, com mirantes, monumentos, museus e as igrejas devido ao forte apelo patrimonial na história dos municípios.

No bojo do processo de organização espacial da atividade turística, observaramse mudanças nos municípios de Santa Maria e Silveira Martins quanto às atividades, arquitetura dos prédios e casas, hábitos e costumes da sociedade e a rotina dos produtores rurais que passaram a trabalhar com Turismo.

No espaço territorializado pelo Turismo encontram-se antigas edificações que eram usadas para o comércio no século passado e que estão sendo (re) funcionalizadas para atender a atividade turística. A Rota Turística Gastronômica de Santa Maria e Silveira Martins além valorizar a cultura local, foi capaz de contribuir na economia dos produtores rurais e na preservação ambiental dos municípios de Santa Maria e Silveira Martins, fortalecendo a auto-estima da população local.

Em relação à organização e à preparação, a atividade turística no meio rural desenvolvida na Rota Turística e Gastronômica se mostrou preocupada em planejar e organizar a rota, pois houve o interesse em garantir um suporte técnico aos novos estabelecimentos e aos antigos de igual forma, mostrando-se consciente por parte dos protagonistas a necessidade de desenvolver o Turismo que busque a participação da comunidade local.

Houve o cuidado em preparar tanto o local para receber turistas com sinalização turística, pois foi realizada pesquisa e um estudo prévio para identificar as potencialidades de Santa Maria e Silveira Martins. Posteriormente, houve apoio do setor público para que os proprietários realizassem cursos que visassem a qualificação e o aprimoramento das pessoas envolvidas diretamente na atividade turística.

Assim percebeu-se que a Rota Turística Gastronômica possui uma diversidade de atrativos que representam diferentes territorialidades e que podem ser melhores aproveitadas por meio de pequenos roteiros integrados. A partir disso, a rota irá atender 
a diversos públicos, de diferentes idades e interesses e também possibilitará o desenvolvimento local para os municípios de Santa Maria e Silveira Martins.

\section{REFERÊNCIAS}

CANDIOTTO, L. Z. P. Turismo rural na agricultura familiar: uma abordagem geográfica do circuito italiano de Turismo rural (CITUR), município de Colombo - PR. 2007. 439 f. Tese (Doutorado em Geografia) - Universidade Federal de Santa Catarina, Florianópolis, 2007.

CASTRO, N. A. R de. O lugar do turismo na ciência geográfica: contribuições teórico-metodológicas à ação educativa. 2006. 311 f. Tese (Doutorado em Geografia) Universidade de São Paulo, São Paulo, 2006.

CASTROGIOVANNI, A. C. A geografia do espaço turístico, como construção complexa da comunicação. 2004. 335 f. Tese (Doutorado em Comunicação Social) Pontifícia Universidade Católica do Rio Grande do Sul, Porto Alegre, 2004.

CORIOLANO, L. N. M. T. Do local ao global: o turismo litorâneo cearense. São Paulo: Papirus, 2000.

GIDDENS, A. As conseqüências da modernidade. São Paulo: UNESP, 1991.

HAESBAERT, R. O mito da desterritorialização: do fim dos territórios à multiterritorialidade. Rio de Janeiro: Bertrand Brasil, 2004.

IBGE. Disponível em: <http://www.ibge.gov.br/cidadesat/topwindow.htm>. Acesso em: 20/02/2009.

ISAIA, A. Os sonhos de emancipação e as frustrações, na história de Silveira Martins (III). Jornal A Razão, Santa Maria, 22 abr. 1987.

KARSBURG, A. de. O. Sobre as ruínas da velha matriz: Religião e política em tempos de ferrovia (Santa Maria - Rio Grande do Sul - 1880/1900). Santa Maria: Ed. UFSM, 2007.

LINDNER, M. Turismo rural e desenvolvimento local: estudo da Rota Gastronômica de Santa Maria - Silveira Martins. 2007. Dissertação (Mestrado em Extensão Rural) Universidade Federal de Santa Maria, Rio Grande do Sul, 2007.

LUCHIARI, M. T. D. P. Turismo e meio ambiente na mitificação dos lugares. Turismo em análise, São Paulo, ano 11, n. 1, p. 35-43, mai. 2000.

ORGANIZAÇÃO MUNDIAL DO TURISMO (OMT). Guia de desenvolvimento do turismo sustentável. Porto Alegre: Bookman, 2003. 
PORTAL QUARTA COLÔNIA. Conheça Silveira Martins. [2009]. Disponível em: <http://www.quartacolonia.com>. Acesso em: 10/02/2009.

RODRIGUES, A. B. Turismo e Espaço: Rumo a um conhecimento transdisciplinar. 2. ed. São Paulo: HUCITEC, 1999.

Turismo e territorialidades plurais - lógicas excludentes ou solidariedade organizacional. In: LEMOS, A. I. G; ARROYO, M; SILVEIRA, M. L. América Latina: cidade, campo e turismo. CLACSO, Conselho Latino- americano de Ciências Sociais, São Paulo, 2006.

RUVIARO, R. E. Silveira Martins: O berço da Quarta Colônia de Imigração Italiana do Rio Grande do Sul. [2007]. Disponível em http:<//www.silveiramartins.rs.gov.br>. Acesso em: 26/01/2009.

SANTOS, M. Espaço e método. 4. ed. São Paulo: Nobel, 1997.

SILVEIRA, M. A. T. da. Turismo, Políticas de Ordenamento territorial e Desenvolvimento. Um foco no Estado do Paraná no contexto regional. São Paulo: FFLCH/USP. Tese de Doutorado, 2002.

SWARBROOKE, J. Setor público e cenários geográficos. São Paulo: Aleph, 2000.

VIERO, L. M. Atlas Municipal Geográfico Escolar. Santa Maria: Diário de Santa Maria, 2003.

Recebido em: 30/08/2009

Aprovado em: 30/09/2009 